\title{
Inhaled therapies in patients with moderate COPD in clinical practice: current thinking
}

REVIEW

This article was published in the following Dove Press journal:

International Journal of COPD

\author{
Amnon Ariel,' Alan Altraja, ${ }^{2,3}$ \\ Andrey Belevskiy, ${ }^{4}$ Piotr W \\ Boros, ${ }^{5}$ Edvardas Danila, ${ }^{6}$ \\ Matjaz Fležar, ${ }^{7}$ Vladimir \\ Koblizek, ${ }^{8}$ Zvi G Fridlender, ${ }^{9}$ \\ Kosta Kostov, ${ }^{10}$ Alvils Krams, ${ }^{\prime \prime}$ \\ Branislava Milenkovic, ${ }^{12}$ \\ Attila Somfay, ${ }^{13}$ Ruzena \\ Tkacova, ${ }^{14}$ Neven Tudoric, ${ }^{15}$ \\ Ruxandra Ulmeanu, ${ }^{16}$ Arschang \\ Valipour ${ }^{17}$
}

'Emek Medical Center, Clalit Healthcare Services, Afula, Israel; ${ }^{2}$ Department of Pulmonary Medicine, University of Tartu, ${ }^{3}$ Lung Clinic, Tartu University Hospital, Tartu, Estonia; ${ }^{4}$ Department of Pulmonology, Russian National Research Medical University, Moscow, Russia; '5ung Pathophysiology Department, National TB and Lung Diseases Research Institute, Warsaw, Poland; ${ }^{6}$ Clinic of Infectious Chest Diseases, Dermatovenereology, and Allergology, Vilnius University, Centre of Pulmonology and Allergology, Vilnius University Hospital,Vilnius, Lithuania; ' University Clinic of Respiratory and Allergic Diseases, Golnik, Slovenia; ${ }^{8}$ Department of Pneumology, University Hospital, Hradec Králové, Czech Republic; ' Institute of Pulmonary Medicine, Hadassah Medical Center, Jerusalem, Israel; ${ }^{10} \mathrm{Clinic}$ of Pulmonary Diseases, Military Medical Academy, Sofia, Bulgaria; "Medical Faculty of Latvian University, Riga East University Hospital, Riga, Latvia; ${ }^{12}$ Clinic for Pulmonary Diseases, Clinical Centre of Serbia, Faculty of Medicine, University of Belgrade, Belgrade, Serbia; ${ }^{13}$ Department of Pulmonology, University of Szeged, Deszk, Hungary; ${ }^{14}$ Department of Respiratory Medicine and Tuberculosis, Faculty of Medicine, PJ Safarik University, Košice, Slovakia; ${ }^{15}$ School of Medicine, Dubrava University Hospital, Zagreb, Croatia; ${ }^{16}$ Marius Nasta Institute of Pneumology, Bucharest, Romania; ${ }^{17}$ Department of Respiratory and Critical Care Medicine, Ludwig Boltzmann Institute for COPD and Respiratory Epidemiology,Vienna, Austria

Correspondence: Arschang Valipour Department of Respiratory and Critical Care Medicine, Ludwig Boltzmann Institute for COPD and Respiratory Epidemiology, Otto Wagner Hospital, 2 Sanatoriumstrasse, Vienna II40, Austria Tel +43 | 910600

Email arschang.valipour@wienkav.at
Abstract: COPD is a complex, heterogeneous condition. Even in the early clinical stages, COPD carries a significant burden, with breathlessness frequently leading to a reduction in exercise capacity and changes that correlate with long-term patient outcomes and mortality. Implementation of an effective management strategy is required to reduce symptoms, preserve lung function, quality of life, and exercise capacity, and prevent exacerbations. However, current clinical practice frequently differs from published guidelines on the management of COPD. This review focuses on the current scientific evidence and expert opinion on the management of moderate COPD: the symptoms arising from moderate airflow obstruction and the burden these symptoms impose, how physical activity can improve disease outcomes, the benefits of dual bronchodilation in COPD, and the limited evidence for the benefits of inhaled corticosteroids in this disease. We emphasize the importance of maximizing bronchodilation in COPD with inhaled dual-bronchodilator treatment, enhancing patient-related outcomes, and enabling the withdrawal of inhaled corticosteroids in COPD in well-defined patient groups.

Keywords: dual bronchodilation, inhaled corticosteroid, LAMA, LABA, tiotropium, anticholinergic

\section{Introduction}

COPD is a progressive lung disease characterized by airflow obstruction that results in breathlessness and disability. ${ }^{1}$ COPD carries a significant burden for patients and health-care systems alike, ${ }^{2-4}$ and rates are reported to be increasing. ${ }^{5}$ In fact, COPD is now the third-leading cause of death worldwide. ${ }^{6}$ In a population-based worldwide study (BOLD initiative), the prevalence of COPD (GOLD stage 2 or higher) identified by postbronchodilator spirometry and questionnaires among individuals of age $\geq 40$ years was $10.1 \%{ }^{7}$ Although a certain proportion of COPD cases remain undiagnosed and the recorded prevalence rates vary among countries, approximately $15 \%-17 \%$ of current smokers and as many as 4\%-12\% of non- or ex-smokers develop COPD. ${ }^{8,9}$ COPD limits daily activities, affecting work and family life. ${ }^{10,11}$ A substantial proportion of patients with mild-moderate COPD (GOLD stage 1 and 2) report poor health, ${ }^{12}$ impaired health-related quality of life (HRQoL), ${ }^{5}$ and exercise limitation, often associated with dynamic hyperinflation during daily activities. ${ }^{13,14}$ Indeed, according to a recent report by O'Donnell et al, patients with COPD stage 1 and 2 have both impaired exercise capacity and increased breathlessness at isotonic exercise when compared with age- and sex-matched controls. ${ }^{13}$ Impairment in exercise tolerance may in turn promote a sedentary lifestyle in patients with COPD, with inactivity levels rising dramatically over the course of the disease. ${ }^{15,16}$ Furthermore, more than a third of patients with mild airflow limitation develop COPD exacerbations, ${ }^{17}$ with 
a subsequently heightened risk of future exacerbations. ${ }^{18}$ Importantly, half of the patients with mild exacerbations of COPD do not report them as such at clinical visits, although exacerbations have been demonstrated to influence QoL and daily activities. ${ }^{19}$ Importantly, even mild-moderate COPD, especially when presenting with symptoms of chronic bronchitis, has been associated with increased mortality. ${ }^{20,21}$

This article summarizes the current scientific evidence and expert opinion on key topics related to the pharmacological treatment of moderate COPD. These include the symptom burden associated with moderate airflow obstruction, the relevance of physical activity on disease outcomes, the value of long-acting dual bronchodilation, and the role of inhaled corticosteroids (ICSs) in COPD. For this purpose, experts from the COPD Platform, a collaboration among physicians from eleven Central and Eastern European countries, aimed at further understanding COPD and conducting clinical research in the region, ${ }^{22}$ discussed the mentioned topics during a roundtable discussion in April 2016, and together with invited experts subsequently analyzed the scientific evidence via multiple exchanges over email.

\section{Risk factors and lung-function decline in COPD}

Smoking is a widely acknowledged risk factor for COPD. According to a recent Finnish study, $11.4 \%$ and $22.8 \%$ of a cohort of heavy smokers had developed COPD by 3 and 6 years of follow-up, respectively. ${ }^{23}$ Developing COPD, however, does not solely depend on smoking exposure. Lange et al showed that $26 \%$ of people under the age of 40 years who had low baseline forced expiratory volume in 1 second $\left(\mathrm{FEV}_{1}\right.$; $<80 \%$ predicted) had developed COPD within 22 years of observation compared with $7 \%$ of those with baseline $\mathrm{FEV}_{1}$ $>80 \% .{ }^{24}$ These findings suggest that early-life risk factors may contribute to COPD beyond the effects of smoking. In fact, in a European study conducted over 9 years, patients aged 20-45 years with one or more childhood disadvantage factors (maternal asthma, paternal asthma, childhood asthma, maternal smoking, or childhood respiratory infections) showed significantly lower $\mathrm{FEV}_{1}$ levels than other patients of the same age. The degree of $\mathrm{FEV}_{1}$ decrease correlated with the number of risk factors present, as did the presence of COPD at study close. ${ }^{25}$ Awareness of such risk factors may lead to earlier interventions and potentially to a reduction in the delays seen in achieving a diagnosis of COPD. The absence of spirometry data in clinical practice is a major contributor to delays in patient diagnosis. ${ }^{26,27}$ This may result in unobserved disease progression and subsequent clinical presentation of more advanced disease. ${ }^{28-30}$ Indeed, in a subset of 366 patients with COPD identified from

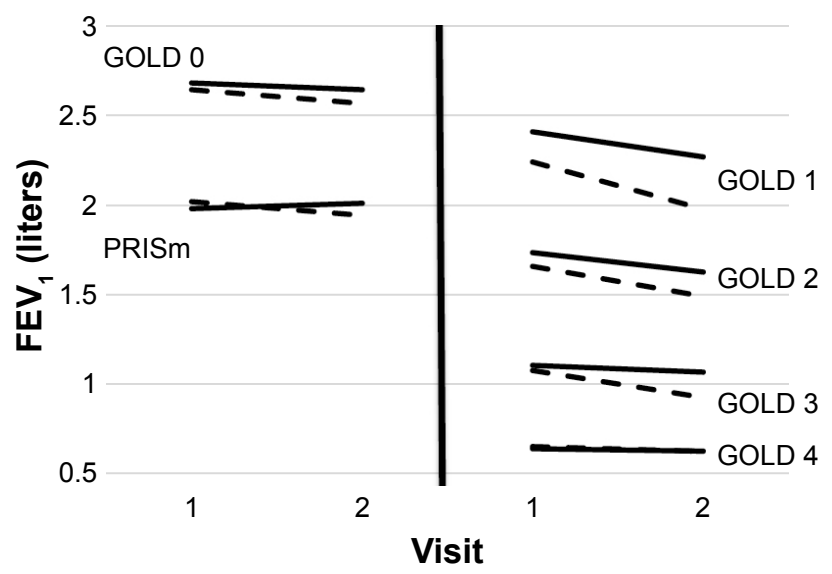

Figure I Estimated changes in FEV, by GOLD group and severe-exacerbation status.

Notes: The plot demonstrates that for each GOLD classification, those individuals with at least one severe exacerbation (dotted lines) had faster declines in FEV, on average compared with those who did not (solid lines). GOLD 0, no airway obstruction; GOLD I, mild; GOLD 2, moderate; GOLD 3, severe; GOLD 4, very severe. Reprinted with permission of the American Thoracic Society. Copyright () 2017 American Thoracic Society. Dransfield MT, Kunisaki KM, Strand MJ, et al. 2017 Acute exacerbations and lung function loss in smokers with and without COPD. Am J Respir Crit Care Med. 2017;195:324-330.32 The American Journal of Respiratory and Critical Care Medicine is an official journal of the American Thoracic Society.

Abbreviation: PRISm, preserved ratio-impaired spirometry.

a US patient database, 50\% suffered from moderate disease (GOLD 2) at the time of diagnosis, while $31 \%$ already had GOLD 3 (severe) or GOLD 4 (very severe) COPD. ${ }^{31}$

Such delays in diagnosing COPD may have several implications. In a large multicenter study, Dransfield et al observed lung-function decline over 5 years at a greater rate in patients with mild-moderate (GOLD 2) COPD than in those with more severe disease. ${ }^{32}$ According to another study, the fastest decline in $\mathrm{FEV}_{1}$ occurs during even mild (GOLD 1) COPD. ${ }^{33}$ The decline in lung function was increased further in patients who had already suffered a severe exacerbation at the time of the first visit (Figure 1). ${ }^{32}$ Therefore, preserving lung function early in the course of the disease may be considered an important goal of therapy to reduce morbidity and mortality. ${ }^{34-36}$

From a therapeutic point of view, it is needless to say that smoking cessation at any stage of the disease can prevent clinically significant airway obstruction and slow down the rate of decline in lung function, ${ }^{37}$ thus benefiting long-term outcomes..$^{38}$ This effect is independent of sex, age, or baseline lung function, indicating that it is never too late to derive benefit from smoking cessation.

\section{Rationale for maximizing bronchodilation in patients with moderate COPD}

Long-acting muscarinic antagonists (LAMAs) selectively block receptor binding to reduce the bronchoconstrictive effects of acetylcholine on smooth-muscle cells in the 
lungs. ${ }^{39}$ Long-acting $\beta_{2}$-adrenoceptor agonists (LABAs) further promote a bronchodilation effect through smoothmuscle relaxation via the $\beta_{2}$-adrenergic receptors ${ }^{40}$ and through inhibition of acetylcholine release..$^{41}$ On the other hand, anticholinergics interfere with PKC inhibition of the downstream signaling of the $\beta_{2}$-adrenergic receptor. ${ }^{42}$ It is worth noting that with LAMAs acting predominantly within the proximal sections of the lung and LABAs typically within the distal sections, they provide a complementary effect on lung function. ${ }^{39,43}$

Treating patients with moderate COPD using bronchodilators may help to preserve and protect lung function, ${ }^{44}$ increase exercise capacity, ${ }^{45}$ reduce exacerbation rates, ${ }^{44,46}$ and reduce symptoms, resulting in better health status, lower disease burden, and improvements in overall QoL..$^{47,48} \mathrm{In}$ fact, a recent study of inhaled tiotropium in patients with early-stage chronic COPD (GOLD stage 1 or 2) indicated that the annual decline in $\mathrm{FEV}_{1}$ measured after bronchodilator use was significantly less in the tiotropium group than the placebo group $(29 \pm 5 \mathrm{~mL}$ per year vs $51 \pm 6 \mathrm{~mL}$ per year, $P=0.006$ ), indicating a potentially disease-modifying effect of long-acting anticholinergic therapy when established early in the disease course. ${ }^{49}$ Whether these benefits extend to the level of a survival benefit remains to be established. Post hoc analyses of both the TORCH and UPLIFT studies suggested a survival benefit of sustained bronchodilation in moderate-severe COPD; however, these findings have not been formally proven in prospective studies. ${ }^{36,50}$

There is emerging scientific evidence for the use of fixeddose combinations of LAMAs and LABAs with the intention of achieving maximal and sustained bronchodilation with subsequent clinical benefits. In this context, we discuss results from recent randomized controlled trials (RCTs) investigating the effects of dual bronchodilation on various clinical outcome measures in patients with COPD..$^{48,51-54}$

\section{Preserving and protecting lung function via pharmacological treatment}

Recent studies have demonstrated the superiority of LAMALABA combinations compared with LAMA or LABA monotherapy with respect to lung function, symptoms, and QoL in the first-line setting of patients with moderate COPD. ${ }^{50,55-58}$ In a double-blind, placebo-controlled, multicenter, Phase III, incomplete crossover study by Beeh et al that enrolled 259 patients, a fixed-dose combination of tiotropium and olodaterol significantly improved lung function versus its individual components, with a 6-week improvement in $\mathrm{FEV}_{1}$ area under the curve to 24 hours $\left(\mathrm{AUC}_{0-24}\right)$ of $244 \mathrm{~mL}$ compared with $117 \mathrm{~mL}$ and $129 \mathrm{~mL}$ for tiotropium and olodaterol alone, respectively. ${ }^{58}$

In a post hoc analysis of 5,162 patients enrolled in the combined TONADO 1 and 2 Phase III trials, Ferguson et al demonstrated comparable improvements in $\mathrm{FEV}_{1} \mathrm{AUC}_{0-3}$ with dual bronchodilation with tiotropium and olodaterol versus the monocomponents in both treatment-naïve and pretreated patients. ${ }^{57}$ Interestingly, improvements in lung function from baseline were generally greater in patients with GOLD stage 2 COPD than those with GOLD stage 3-4 COPD ${ }^{55}$ Furthermore, it has been shown using the fixed-dose combination of tiotropium and olodaterol that the LAMA and LABA components of dual bronchodilation have an additive effect on lung function, resulting in improved functional residual capacity, residual volume, breathlessness, and QoL compared with either component as monotherapy. ${ }^{38,55,56,58,59}$ Statistically significant improvements in hyperinflation expressed as a reduction of functional residual capacity from baseline at 2.5 hours postdose were also observed, with $-435 \mathrm{~mL}$ and $-431 \mathrm{~mL}$ for olodaterol and tiotropium monotherapy, respectively, compared with $-547 \mathrm{~mL}$ for the combination therapy. ${ }^{56}$

Clinically meaningful improvements in HRQoL have been recorded with the fixed-dose combination of tiotropium and olodaterol, showing improvements in St George's Respiratory Questionnaire (SGRQ) total score after 12 weeks by 4.89 versus placebo and 2.49 versus tiotropium alone. ${ }^{55}$ Importantly, the incidence of adverse events is comparable between the fixed-dose combination and tiotropium or olodaterol monotherapy. ${ }^{38,55,56}$ When considering these results, it should be noted that the patient populations in these studies varied, with the inclusion of high proportions of patients with moderate COPD (GOLD stage 2$)^{51}$ or comorbidities, ${ }^{60}$ as well as pretreated ${ }^{38,56}$ and treatment-naïve patients. ${ }^{38,61}$

Other dual-action bronchodilator combinations have shown similar benefits. Donohue et al conducted a 24-week study of umeclidinium (UMEC)-vilanterol (VI) against the individual components or placebo, finding that all active treatments produced statistically significant improvements in trough $\mathrm{FEV}_{1}$ compared with placebo on day $169(0.072-0.167 \mathrm{~L}$, all $P<0.001)$, that the increase in trough $\mathrm{FEV}_{1}$ with UMEC (62.5)-VI $(25 \mu \mathrm{g})$ was significantly greater than with monotherapies $(0.052-0.095 \mathrm{~L}, P \leq 0.004)$, and that statistically significant HRQoL improvements were seen in SGRQ scores compared with placebo. ${ }^{62}$ In the SHINE study, an indacaterol and glycopyrronium combination was assessed against the individual components in patients with moderate-severe COPD. Trough $\mathrm{FEV}_{1}$ was statistically higher in the combination arm than the single agents $(P<0.001) \cdot{ }^{63}$ SGRQ scores in 
this study at week 12 were statistically higher for the combination than placebo $(P<0.001)$ and glycopyrronium $(P=0.02)$, but this finding was not seen against indacaterol or with any single agent vs placebo. Overall, there is increasing evidence for a beneficial effect of dual bronchodilation in patients with COPD compared with single agents.

\section{Bronchodilators and exercise limitation}

Patients in the early stages of COPD suffer from noticeable breathlessness on exertion, predominantly owing to dynamic hyperinflation, ${ }^{13,64}$ and this phenomenon is present even during daily activities. ${ }^{14}$ In turn, dyspnea during exercise is likely to contribute to the significant drop in activity levels seen in patients with mild-moderate COPD. ${ }^{15}$ A controlled multicenter study by Troosters et al involving 70 patients with COPD and 30 healthy controls demonstrated a 29\% reduction in the number of steps per day and a 59\% reduction in the time spent on activities at moderate intensity in patients with GOLD stage 2 COPD compared with control individuals. ${ }^{65}$

Sedentary behavior and lack of physical activity are strong and independent predictors of all-cause mortality in COPD. ${ }^{66-69}$ Taking steps to maintain regular exercise thus has a positive impact on QoL and COPD progression, ${ }^{67}$ preventing a downward spiral in physical function and conditioning. ${ }^{70}$ Indeed, pulmonary rehabilitation (PR) is regarded as being one of the most effective nonpharmacological treatments for people with COPD, leading to improvements in exercise tolerance, dyspnea, and HRQoL. ${ }^{71,72}$ Importantly, some of these benefits may be achieved by improvements in accessible alveolar lung volume, whereas patients with severe diffusion-capacity impairment and presence of ventilation inhomogeneity appear to experience smaller improvements in exercise tolerance. ${ }^{73}$ By the addition of a long-acting anticholinergic bronchodilator to PR, clinically meaningful improvements in dyspnea and health status have been seen over PR alone. ${ }^{74}$ Studies on the effect of dual bronchodilation in association with $\mathrm{PR}$ in patients with COPD are still lacking.

It may be suggested that improving lung function and reducing elevated lung volume by sustained bronchodilation can reduce dynamic hyperinflation in COPD and thus contribute to patients' improved exercise tolerance. The introduction of dual-bronchodilator treatments into real-life clinical practice may further facilitate increased exercise capacity. ${ }^{75,76}$ In a 12-week, double-blind, placebo-controlled study involving 404 patients, combined tiotropium and olodaterol provided a $21 \%$ improvement in endurance shuttle walking versus placebo. ${ }^{75}$ Similarly, a double-blind, double-dummy, threeperiod crossover study of 85 patients revealed that combined glycopyrronium and indacaterol significantly improved patients' exercise endurance time compared with placebo. ${ }^{76}$ Once published, the recently completed PHYSACTO ${ }^{77}$ study should provide additional clarity on the physical activity benefits of dual bronchodilation. This randomized, partially double-blinded, placebo-controlled, parallel-group trial involving patients from 34 multinational sites looks at multicomponent interventions (tiotropium, tiotropium + olodaterol, or tiotropium + olodaterol + exercise training) that are designed to support behavior change related to physical activity. ${ }^{77}$ Recently, the MORACTO 1 and 2 studies assessed the effects of tiotropium-olodaterol on inspiratory capacity and exercise-endurance time in patients with moderate-severe COPD. Tiotropium (2.5/5 $\mu \mathrm{g})$-olodaterol $(5 / 5 \mu \mathrm{g})$ provided significant improvements in inspiratory capacity versus placebo and monotherapies $(P<0.0001)$ and significant improvements in exercise-endurance time versus placebo $(P<0.0001){ }^{78}$ It would be of interest to perform a prospective study to assess $\mathrm{PR}$ by directly comparing a LAMA-LABA combination plus PR to the LAMA-LABA combination alone.

However, a number of questions remain unanswered in this context. Will the patients with COPD actually improve their activity levels in a real-life setting after the initiation of optimal bronchodilator treatment? Is there a threshold of irreversibility with regard to physical deconditioning based on biological grounds, such as systemic inflammation? And what is the role of such comorbidities as heart failure in exercise-capacity limitations?

\section{The effect of bronchodilators on exacerbation rates in COPD}

An important consideration in the treatment of COPD is the prevention of exacerbations. Although ICSs have been traditionally viewed as the main treatment for patients at risk of exacerbations (especially for postbronchodilator $\mathrm{FEV}_{1} \leq 50 \%$ predicted value), there is accumulating evidence to suggest an important role for bronchodilators in the prevention of exacerbations. ${ }^{79-82}$ In a previous clinical trial conducted in 37 countries, 5,993 patients were randomized to receive 4 years of treatment with either $18 \mu \mathrm{g}$ once-daily tiotropium or placebo delivered by matching inhalation devices. The results showed that tiotropium significantly reduced exacerbation rates versus placebo in largely pretreated (with medicines other than LAMAs) patients with GOLD stage 2 COPD. ${ }^{46}$ 
Vogelmeier et al subsequently demonstrated superiority of LAMAs over LABAs in reducing exacerbation rates in COPD, suggesting the presence of various mechanisms and pathways that anticholinergic and $\beta_{2}$-sympathomimetic agents affect, leading to fewer exacerbations. ${ }^{83} \mathrm{~A}$ similar signal was observed in patients with severe COPD when using a LABA with 24-hour efficacy. ${ }^{84}$ Combining LAMA and LABA agents, however, may exert additive effects that could further reduce the number of exacerbations in COPD. Indeed, combination of sustained bronchodilation with subsequent lung-volume reduction might contribute to patent airways, thus protecting patients from fluctuations in the severity of airflow obstruction that potentially lead to an exacerbation..$^{50,85}$ A recent study investigating the effects of tiotropium and indacaterol on stable patients with moderatesevere COPD showed that the vital capacity in these patients had increased at 1 hour postadministration, but not the transpulmonary pressure curve, indicating that it is possible to achieve a positive effect on gas exchange without risking small-airway damage. ${ }^{86}$

Furthermore, in addition to having low-level antiinflammatory effects, both LAMAs and LABAs have demonstrated reductions in mucus production and improvements in mucus clearance, which in turn may reduce exacerbation risk by a robust increase in the threshold of sensitivity to exacerbation-precipitating triggers. ${ }^{87-89}$ Finally, bronchodilators have been demonstrated to reduce both cardiac preload and afterload, thus improving cardiac function. ${ }^{90}$ Given that left heart failure is considered an important trigger of COPD exacerbations, ${ }^{91}$ improvements in cardiovascular morbidity associated with long-term maintenance-bronchodilator treatment may contribute to the stability of COPD. ${ }^{92,93}$

As expected, a combination of two bronchodilators may significantly improve lung function compared with the combination of a single bronchodilator (usually a LABA) with an ICS. Indeed, Rabe et al demonstrated superiority of a free combination of tiotropium and formoterol over a fixed-dose combination of salmeterol and fluticasone for FEV AUC $^{94}$ These findings were further strengthened by the introduction of fixed-dose combination dual-bronchodilator therapy. After 6 weeks of once-daily dual bronchodilation with tiotropium $(5 / 5 \mu \mathrm{g})$ and olodaterol $(2.5 / 5 \mu \mathrm{g})$ compared with twicedaily salmeterol $(50 / 500 \mu \mathrm{g})$ and fluticasone propionate $(50 / 250 \mu \mathrm{g})$, statistically significant improvements were seen in $\mathrm{FEV}_{1} \mathrm{AUC}_{0-12}(P<0.0001$ for all comparisons $) .{ }^{50}$ The combination of tiotropium and olodaterol was also superior to the combination of salmeterol and fluticasone propionate for improving secondary lung-function end points, including
$\mathrm{FEV}_{1} \mathrm{AUC}_{0-24}(P<0.0001$ for all comparisons $)$. A fixed-dose combination of indacaterol and glycopyrronium similarly offered a significant and clinically meaningful improvement in $\mathrm{FEV}_{1} \mathrm{AUC}_{0-12}$ at week 26 compared with that achieved with a combination of salmeterol and fluticasone. ${ }^{95}$ Similar findings with respect to lung-function improvements over LABA-ICS combinations have been observed with other dual-bronchodilator combinations, such as umeclidiniumvilanterol ${ }^{96}$ and aclidinium-formoterol..$^{93,97}$

A previous post hoc analysis from a clinical trial of LAMA-LABA versus LABA-ICS combinations demonstrated lower exacerbation rates with the dual-bronchodilator combination, indicating that the aforementioned pleiotropic effects of dual bronchodilation may be more potent than the anti-inflammatory effects of ICSs on the course of COPD. More recently, results from a prospective RCT (FLAME) confirmed superiority of LAMA-LABA over LABA-ICS combinations in reducing exacerbation rates in patients with COPD at risk of exacerbations. ${ }^{52}$ This study was a year-long RCT designed to compare the annual number of COPD exacerbations as the primary end point between LAMA-LABA (indacaterol-glycopyrronium once daily) and LABA-ICS (salmeterol-fluticasone twice daily) study groups. The LAMA-LABA combination not only showed noninferiority but also superiority over the LABA-ICS combination with an $11 \%$ lower annual rate of COPD exacerbations plus a $16 \%$ lower risk of exacerbation reflected in a longer time to first exacerbation in the LAMA-LABA group versus the LABA-ICS group. ${ }^{52}$ However, it should be noted that "noninferiority only" was demonstrated for the $20 \%$ of patients with COPD in the study who had a history of two or more exacerbations. This is of specific importance, as in the recent GOLD guidelines, ${ }^{98}$ patients are stratified into different risk groups with respective treatment recommendations based on symptom load and exacerbation history, but not on $\mathrm{FEV}_{1}$. Indeed, a recent analysis from a cohort of 3,500 patients with stable COPD in Central and Eastern Europe ${ }^{99}$ showed that $35 \%$ of patients in group D according to the previous version of the GOLD guidelines ${ }^{100}$ would move to group B according to the GOLD 2017 revision, because of a lack of real exacerbations. ${ }^{101}$ Of note, the majority of these patients (71\%) were on ICS treatment, and according to GOLD 2017 should not receive ICSs any longer. It remains to be determined whether and to what extent the guideline recommendations on the use of ICS-containing regimens will be translated into real-life prescription behavior. ${ }^{98}$ Furthermore, these studies were undertaken using LABA-ICS combinations, so until the results of ongoing research to address the effect and role of 
adding ICSs to LAMA-LABA combinations are available, ${ }^{102}$ the wider spectrum of the usefulness of ICSs in the treatment pathway cannot be fully elucidated.

In addition to improvements in patient outcomes, dual bronchodilation also seems to reduce demand for health-care resources, with LAMA-LABA patients requiring significantly less rescue medication than patients receiving LAMA or LABA alone. ${ }^{103,104}$ Whether dual bronchodilation will demonstrate superiority over treatment with single bronchodilators for moderate-severe exacerbation rates will be assessed in the Phase III DYNAGITO trial, which is a prospective RCT investigating a tiotropium-containing LAMA-LABA combination versus bronchodilator monotherapy. ${ }^{105}$

On the basis of the accumulating evidence for dual bronchodilators with respect to lung function, symptoms, HRQoL, and exacerbation rates, first-line treatment with LAMA-LABA fixed-dose combinations may be considered in the majority of treatment-naïve patients with symptomatic COPD. In contrast, the role of ICS-containing drug regimens in COPD needs further personalized evaluation. ${ }^{98,106}$

\section{The role of ICSs in COPD ICS monotherapy in COPD}

The paradigm of beneficial effect of ICSs in asthma and the similarity of airway symptoms in the two diseases have led to the use of ICSs being extended to COPD. However, unlike asthma, steroid resistant inflammation occurs in most patients with COPD, explaining the ineffectiveness of ICSs in this disease. ${ }^{107}$ Early trials of ICSs in COPD conducted prior to the availability of long-acting bronchodilators showed symptomatic benefit without affecting FEV decline $_{1}$ or mortality. ${ }^{108-110}$ The main beneficial effect of ICSs in COPD, a modest decrease in moderate-severe exacerbations was largely limited to patients with severe airflow limitation. ${ }^{111}$ Critical appraisal revealed important methodological issues that underlay a significant overestimate of this salutary effect. ${ }^{112}$

\section{ICS-LABA in COPD}

When ICS-LABA combination inhalers became available, the problem of "copy-pasting" ICS-based asthma therapies onto COPD recurred. The TORCH RCT investigated the effects of an ICS-LABA combination on mortality and key secondary outcomes in severe COPD. ${ }^{50}$ This trial, notable for complete follow-up (intention-to-treat) for survival, is often perceived as "almost achieving" a statistically significant survival benefit. However, post hoc factorial analysis found a statistically significant $19 \%$ survival advantage to the
LABA component (salmeterol), but not to the ICS component (fluticasone). ${ }^{113}$ Interpretation of the TORCH results pertaining to benefits in exacerbations and decline in $\mathrm{FEV}_{1}$ and QoL is prone to bias of differential dropout, owing to incomplete follow-up for these secondary end points. ${ }^{114}$

\section{ICS use as per GOLD reports}

Since 2011, in acknowledgment of the aforementioned observations and the demonstrated superiority of long-acting bronchodilators over ICSs in improving lung function and exercise capacity, ${ }^{115}$ GOLD COPD recommendations against ICS monotherapy limited ICS use in COPD to ICS-LABA combinations only. This further emphasizes the dominant contribution of the long-acting bronchodilator (in this case, LABA) component of ICS-LABA combinations in COPD and in contrast to the dominant role of ICSs versus bronchodilators in asthma. Given the increasing evidence for the effectiveness of dual long-acting bronchodilation in improving key COPD-outcome measures, the updated GOLD 2017 report recommends that ICS-containing drug regimens be restricted to patients with severe airflow limitation and frequent exacerbations despite maximized bronchodilator treatment. ${ }^{98}$

\section{The challenge of implementing guidelines}

As many as two-thirds or more of primary care physicians ${ }^{116}$ and a third of respiratory specialists do not follow the GOLD recommendations in clinical practice. ${ }^{117}$ Using a large primary-care database from the UK, Brusselle et al recently demonstrated that $25 \%$ of patients receive ICS-containing treatment within the first year of treatment initiation, with almost $100 \%$ receiving triple-inhaler therapy within 8 years of diagnosis. ${ }^{118}$ Similarly, both Price et al and Barrecheguren et al reported that a high proportion of patients with mildmoderate COPD were receiving ICS-based treatment in clinical practice. ${ }^{119,120}$ Several factors contribute to the discrepancy between guidelines and real-life practice. The long-standing underutilization of spirometry and unfamiliarity with its use in primary care, ${ }^{121-125}$ together with erroneous beliefs regarding the benefits of ICSs in COPD and overused asthma-COPD overlap in diagnostic labeling, all contribute to difficulties in differentiating COPD from asthma. ${ }^{124-126}$ The complexity of the GOLD classification of COPD and the ever-increasing multiplicity of inhaler options may add difficulties in proper implementation of the guidelines. ${ }^{98}$ Habitual prescribing patterns and existing prescriptions from a prior health-care professional may contribute to delays in the clinical implementation of recommendations from 
updated guidelines. ${ }^{127}$ Inadequate symptom control and/or persistent breathlessness due to common comorbidities may prompt the addition of inhaled therapy. These factors may call for increased education and awareness, particularly for primary-care physicians and specialists, who frequently initiate treatment.

\section{ICSs and pneumonia in COPD}

In patients not fulfilling the aforementioned criteria, ICS use may have an unfavorable risk:benefit ratio. ${ }^{128}$ Prolonged ICS use in these patients has been associated with increased rates of pneumonia, tuberculosis, osteoporosis, cataracts, diabetes, and oropharyngeal candidiasis. ${ }^{129,130}$ Whether this increase is class-related or brand-related remains to be decided. ${ }^{131-133}$ Again, the TORCH trial drew attention to the adverse associations linking ICS use in COPD to the events of pneumonia. ${ }^{134}$ According to a recent meta-analysis, the estimated unadjusted risk of pneumonia associated with ICSs was increased in both randomized trials (RR 1.61) and in observational studies (OR 1.89), without evidence of an increase in case fatality. ${ }^{135}$ However, a greater number of patients with COPD receiving ICSs are hospitalized due to severe pneumonia than those not receiving ICSs; therefore, a possibility exists that more patients with COPD will die from pneumonia, even if the case-fatality rate is the same once hospitalized. ${ }^{136}$ The risk of pneumonia decreases, however, by $50 \%$ within 4 months of ICS discontinuation. ${ }^{137}$ It should be emphasized, however, that for patients in whom ICSs are correctly indicated (as detailed herein), their benefits could outweigh the increased risk of pneumonia.

\section{Asthma and COPD overlap}

In recognition of patients presenting with clinical features of both asthma and COPD, associated with an increased burden of symptoms and exacerbations, ${ }^{138,139}$ both GOLD and GINA jointly formulated a 2015 document recommending that these patients with asthma-COPD overlap should be treated with ICSs, irrespective of their lung-function impairment, to prevent asthma-related morbidity and mortality. ${ }^{100,140}$ The stated prevalence of this group of patients is $5 \%-45 \%$ of those with COPD, and accounted for $7 \%$ of patients with COPD in the Central and Eastern Europe POPE study. ${ }^{99}$ The 2017 version of the GOLD report treats asthma-COPD overlap as an overlap phenomenon, rather than a distinct syndrome, ${ }^{98}$ and the 2015 appendix developed by the GINA and GOLD committees addressed the difficulty of this clinical definition, suggesting several characteristic clinical features. ${ }^{141}$ These include a history of asthma and other respiratory symptoms before the age of 40 years, airflow limitation not being fully reversible, a history of allergies, and the presence of eosinophils and/or neutrophils in the sputum. These patients have been largely excluded from both asthma and COPD trials, meaning that there is no documented evidence on the effective management of this group. Therefore, the presumed effectiveness of ICSs in patients with asthmaCOPD overlap remains to be established, especially as the underlying inflammatory endotype is often noneosinophilic and thus unresponsive to treatment with ICSs and probably also with anti-IL5. ${ }^{142-144}$

\section{Peripheral blood eosinophil count in COPD}

Evidence of eosinophilic inflammation using blood eosinophilia as a surrogate marker may be a useful predictor of a beneficial response to ICS treatment in COPD, as higher effectiveness of ICS-containing regimens on lung function and exacerbations has been reported in patients with COPD who have higher peripheral blood eosinophil counts. ${ }^{145-148}$ A reanalysis of the former ISOLDE study suggests that a baseline blood eosinophil count $\geq 2 \%$ identifies those patients with COPD who may benefit from ICS-containing regimens, leading to a reduction in the rate of decline in $\mathrm{FEV}_{1}{ }^{149}$ Some patients with COPD have predominantly eosinophilic inflammation and might respond to high doses of ICSs and newly developed antieosinophil therapies. ${ }^{144}$ Recent results indicated that patients with GOLD 3 or GOLD 4 COPD and eosinophil counts of more than 300 cells/ $\mu \mathrm{L}$ (or $4 \%$ ) were more likely to experience exacerbations following ICS withdrawal. ${ }^{148}$ In the GOLD 2017 revised guidelines, however, the current use of blood eosinophils to guide ICS treatment in COPD is not recommended, owing to the lack of prospective RCTs using circulating eosinophils to titrate and/or target the use of ICSs in treating the disease..$^{98}$ Except where concomitant asthma is present, the inclusion of ICSs based on peripheral eosinophil count requires further validation before it can be generally recommended in therapeutic regimens for patients with COPD.

\section{ICS withdrawal in COPD}

Previous studies have indicated that abrupt withdrawal of ICSs increases the risk of exacerbations and results in some worsening of lung function. ${ }^{140,154} \mathrm{~A}$ recent review of RCTs involving ICS withdrawal, however, supports the withdrawal of ICSs in patients with moderate COPD at low risk of exacerbation who are receiving adequate background therapy with long-acting bronchodilators. ${ }^{155}$ The recent WISDOM 
study demonstrated that apart from a mild $40 \mathrm{~mL}$ decrease in $\mathrm{FEV}_{1}{ }^{156}$ there was no increase in exacerbation risk after ICS withdrawal in patients with severe COPD on triple-inhaler therapy. ${ }^{156}$ Importantly, the WISDOM study assessed the possibility of stepwise withdrawal of ICSs from patients with GOLD stage 3-4 COPD and a history of at least one exacerbation during the previous 12 months. ${ }^{156}$ Following 6 weeks of treatment with tiotropium, salmeterol, and fluticasone, patients were randomized for ongoing treatment or stepwise reduction of ICSs. ${ }^{154}$ Over the 3-month withdrawal period, the HR for a first moderate or severe acute exacerbation was 1.06 (95\% CI 0.94-1.19) with ICS withdrawal compared with continued treatment, thereby indicating noninferiority. ${ }^{156}$ A recent meta-analysis of the benefit of ICS withdrawal showed mixed results: although there was no significant increase $(P<0.05)$ in the rate of COPD exacerbation overall, there remained a clinically important increased risk of severe exacerbation $(\mathrm{RR}>1.2) .{ }^{157}$ Withdrawal was also significantly associated with decreased $\mathrm{FEV}_{1}$ and $\mathrm{HRQOL}$ $(P<0.001)$, although not in a clinically important manner. The GOLD 2017 recommendations suggest considering ICS withdrawal in patients with continuing exacerbations despite triple-inhaler therapy (ICS failure). ${ }^{99}$

Although safe in selected patients, ${ }^{154,158}$ implementing ICS withdrawal in clinical practice requires both thoughtful patient management and comprehensive physician education to identify suitable patients and handle the withdrawal process. This sort of decision may be sensitive, especially in cases where patients have been on ICS-containing therapies for a long time. Recently, an algorithm was proposed that provides physicians with a practical guide for the withdrawal of ICSs. ${ }^{160}$ Building on the GOLD recommendations, the GINA-GOLD consensus statement on the asthma-COPD overlap phenotype, and the WISDOM trial, the algorithm provides a stepwise approach to identifying appropriate patients and managing ICS withdrawal. ${ }^{159}$

Consistent with this stepwise recommendation and a recent proposal of phenotype-driven therapy, ${ }^{105}$ the following was suggested: 159

1. review and optimize current COPD management, ensuring clinical stability and optimal long-acting bronchodilator background therapy

2. evaluate the risk-benefit profile of continuing ICSs; in particular, identify whether the patient has asthma-COPD overlap and/or severe airflow limitation with evidence of eosinophilia and frequent exacerbations; if this is the case, continuation of ICSs is currently warranted
3. if the patient does not fulfill the criteria specified in point 2, first ensure optimized bronchodilation with LAMALABA treatment, then perform a stepwise withdrawal of ICSs, reducing the dose every 6-12 weeks

4. follow-up every 3 months for the first year.

Although further validation is required, this proposed algorithm ${ }^{159,160}$ represents an important first step in the safe and effective management of ICS withdrawal.

\section{Conclusion}

There is increasing clinical evidence for the effectiveness of fixed-dose combination dual-bronchodilator treatment in achieving improved patient-related outcomes and decreasing the burden of moderate COPD. Based on clinical improvements, lung-function benefits, and reduced exacerbation rates, together with a favorable safety profile, LAMA-LABA combinations may be considered the first-line treatment for the majority of patients with moderate or severe COPD. Adding an ICS component should generally be reserved for targeted use in patients with frequent exacerbations despite dual bronchodilation with a fixed-dose combination and in patients with a history of and/or clinical signs of asthma. Stepwise ICS withdrawal should be considered in patients with COPD and low exacerbation risk and in those with repeated exacerbations despite triple-inhaler therapy.

The current availability of a plethora of inhalers for COPD management has both advantages and disadvantages. In particular, unfamiliarity with the different classes and functions of the agents, especially among general practitioners, can lead to confusion of both patients and prescribing physicians. While there is an ongoing need for new classes of therapy, comprehensive patient care must also include appropriate education regarding adherence and inhaler technique, as well as nonpharmacological therapies, mainly PR, to ameliorate the frailty of patients with COPD.

\section{Acknowledgments}

This manuscript was prepared with editorial assistance from Fortis Pharma Communications with financial support from Boehringer Ingelheim. All opinions are the authors' own.

\section{Disclosure}

The authors report no conflicts of interest in this work.

\section{References}

1. Cohen JS, Miles MC, Donohue JF, Ohar JA. Dual therapy strategies for COPD: the scientific rationale for LAMA + LABA. Int J Chron Obstruct Pulmon Dis. 2016;11:785-797. 
2. Lopez AD, Shibuya K, Rao C, et al. Chronic obstructive pulmonary disease: current burden and future projections. Eur Respir J. 2006;27:397-412.

3. Pauwels RA, Buist AS, Calverley PM, Jenkins CR, Hurd SS. Global strategy for the diagnosis, management, and prevention of chronic obstructive pulmonary disease: NHLBI/WHO Global Initiative for Chronic Obstructive Lung Disease (GOLD) Workshop summary. Am J Respir Crit Care Med. 2001;163:1256-1276.

4. European Respiratory Society. European Lung White Book. Huddersfield, UK: ERS; 2003.

5. Mathers CD, Loncar D. Projections of global mortality and burden of disease from 2002 to 2030. PLoS Med. 2006;3:e442.

6. World Health Organization. The top 10 causes of death. 2017. Available from: http://www.who.int/mediacentre/factsheets/fs310/en. Accessed October 31, 2017.

7. Buist AS, McBurnie MA, Vollmer WM, et al. International variation in the prevalence of COPD (the BOLD study): a population-based prevalence study. Lancet. 2007;370:741-750.

8. Raherison C, Girodet PO. Epidemiology of COPD. Eur Respir Rev. 2009;18:213-221.

9. Lamprecht B, McBurnie MA, Vollmer WM, et al. COPD in never smokers: results from the population-based Burden of Obstructive Lung Disease study. Chest. 2011;139:752-763.

10. Roche N, Small M, Broomfield S, Higgins V, Pollard R. Real world COPD: association of morning symptoms with clinical and patient reported outcomes. COPD. 2013;10:679-686.

11. Kanervisto M, Paavilainen E, Heikkilä J. Family dynamics in families of severe COPD patients. J Clin Nurs. 2008;16:1498-1505.

12. Coultas DB, Mapel D, Gagnon R, Lydick E. The health impact of undiagnosed airflow obstruction in a national sample of United States adults. Am J Respir Crit Care Med. 2001;164:372-377.

13. O'Donnell DE, Maltais F, Porszasz J, et al. The continuum of physiological impairment during treadmill walking in patients with mildto-moderate COPD: patient characterization phase of a randomized clinical trial. PLoS One. 2014;9:e96574.

14. Hannink JD, van Helvoort HA, Dekhuijzen PN, Heijdra YF. Dynamic hyperinflation during daily activities: does COPD global initiative for chronic obstructive lung disease stage matter? Chest. 2010;137: 1116-1121.

15. Watz H, Waschki B, Meyer T, Magnussen H. Physical activity in patients with COPD. Eur Respir J. 2009;33:262-272.

16. Waschki B, Kirsten AM, Holz H, et al. Disease progression and changes in physical activity in patients with chronic obstructive pulmonary disease. Am J Respir Crit Care Med. 2015;192:295-306.

17. Agusti A, Calverley PM, Celli B, et al. Characterisation of COPD heterogeneity in the ECLIPSE cohort. Respir Res. 2010;11:122.

18. Hurst JR, Vestbo J, Anzueto A, et al. Susceptibility to exacerbation in chronic obstructive pulmonary disease. $N$ Engl J Med. 2010;363: $1128-1138$.

19. Pavord ID, Jones PW, Burgel PR, Rabe KF. Exacerbations of COPD. Int J Chron Obstruct Pulmon Dis. 2016;11:21-30.

20. Mannino DM, Buist AS, Petty TL, Enright PL, Redd SC. Lung function and mortality in the United States: data from the First National Health and Nutrition Examination Survey follow up study. Thorax. 2003; 58:388-393.

21. Ekberg-Aronsson M, Pehrsson K, Nilsson JA, Nilsson PM, Löfdahl CG Mortality in GOLD stages of COPD and its dependence on symptoms of chronic bronchitis. Respir Res. 2005;6:98.

22. Zbozinkova Z, Barczyk A, Tkacova R, et al. POPE study: rationale and methodology of a study to phenotype patients with COPD in Central and Eastern Europe. Int J Chron Obstruct Pulmon Dis. 2016;11:611-622.

23. Toljamo T, Hamari A, Sotkasiira M, Nieminen P. Clinical characteristics of COPD syndrome: a 6-year follow-up study of adult smokers. Ann Med. 2015;47:399-405.

24. Lange P, Celli B, Agustí A, et al. Lung-function trajectories leading to chronic obstructive pulmonary disease. $N$ Engl J Med. 2015;373: $111-122$
25. Svanes C, Sunyer J, Plana E, et al. Early life origins of chronic obstructive pulmonary disease. Thorax. 2010;65:14-20.

26. Minas M, Hatzoglou C, Karetsi E, et al. COPD prevalence and the differences between newly and previously diagnosed COPD patients in a spirometry program. Prim Care Respir J. 2010;19:363-370.

27. Ghattas C, Dai A, Gemmel DJ, Awad MH. Over diagnosis of chronic obstructive pulmonary disease in an underserved patient population. Int J Chron Obstruct Pulmon Dis. 2013;8:545-549.

28. Lindberg A, Berg A, Rönmark E, Larsson LG, Lundbäck B. Prevalence and underdiagnosis of COPD by disease severity and the attributable fraction of smoking. Respir Med. 2006;100:264-272.

29. Walters JA, Hansen E, Mudge P, Johns DP, Walters EH, Wood-Baker R. Barriers to the use of spirometry in general practice. Aust Fam Physician. 2005;34:201-203.

30. Walters JA, Hansen EC, Walters EH, Wood-Baker R. Under-diagnosis of chronic obstructive pulmonary disease: a qualitative study in primary care. Respir Med. 2008;102:738-743.

31. Mapel DW, Dalal AA, Blanchette CM, Petersen H, Ferguson GT. Severity of COPD at initial spirometry-confirmed diagnosis: data from medical charts and administrative claims. Int J Chron Obstruct Pulmon Dis. 2011;6:573-581.

32. Dransfield MT, Kunisaki KM, Strand MJ, et al. Acute exacerbations and lung function loss in smokers with and without COPD. Am J Respir Crit Care Med. 2017;195:324-330.

33. Kim SJ, Lee J, Park JS, et al. Age-related annual decline of lung function in patients with COPD. Int J Chron Obstruct Pulmon Dis. 2016;11:51-60.

34. Celli BR, Decramer M, Asijee GM, Kupas K, Tashkin DP. Effects of tiotropium in patients with COPD with low or high risk of exacerbations: a post-hoc analysis from the 4-year UPLIFT trial. Chronic Obstr Pulm Dis. 2015;2:122-130.

35. Ferguson GT, Fležar M, Korn S, et al. Efficacy of tiotropium + olodaterol in patients with chronic obstructive pulmonary disease by initial disease severity and treatment intensity: a post hoc analysis. Adv Ther. 2015;32:523-536.

36. Celli B, Decramer M, Kesten S, et al. Mortality in the 4-year trial of tiotropium (UPLIFT) in patients with chronic obstructive pulmonary disease. Am J Respir Crit Care Med. 2009;180:948-955.

37. Anthonisen NR. Lessons from the Lung Health Study. Proc Am Thorac Soc. 2004;1:143-145

38. Shavelle RM, Paculdo DR, Kush SJ, Mannino DM, Strauss DJ. Life expectancy and years of life lost in chronic obstructive pulmonary disease: findings from the NHANES III follow-up study. Int J Chron Obstruct Pulmon Dis. 2009;4:137-148.

39. Matera MG, Page CP, Cazzola M. Novel bronchodilators for the treatment of chronic obstructive pulmonary disease. Trends Pharm Sci. 2011; 32:495-506

40. Ejiofor S, Turner AM. Pharmacotherapies for COPD. Clin Med Insights Circ Respir Pulm Med. 2013;7:17-34

41. Cazzola M, Calzetta L, Matera MG. $\beta_{2}$-Adrenoceptor agonists: current and future direction. Br J Pharmacol. 2011;163:4-17.

42. Meurs H, Dekkers BGJ, Maarsingh H, Halayko AJ, Zaagsma J, Gosens R. Muscarinic receptors on airway mesenchymal cells: novel findings for an ancient target. Pulm Pharmacol Ther. 2013;26:145-155.

43. Dale PR, Cernecka H, Schmidt M, et al. The pharmacological rationale for combining muscarinic receptor antagonists and $\beta$-adrenoceptor agonists in the treatment of airway and bladder disease. Curr Opin Pharmacol. 2014;16:31-42.

44. Decramer M, Celli B, Kesten S, Lystig T, Mehra S, Tashkin DP. Effect of tiotropium on outcomes in patients with moderate chronic obstructive pulmonary disease (UPLIFT): a prespecified subgroup analysis of a randomised controlled trial. Lancet. 2009;374:1171-1178.

45. Casaburi R, Maltais F, Porszasz J, et al. Effects of tiotropium on hyperinflation and treadmill exercise tolerance in mild to moderate chronic obstructive pulmonary disease. Ann Am Thorac Soc. 2014;11: 1351-1361. 
46. Jenkins CR, Jones PW, Calverley PM, et al. Efficacy of salmeterol/ fluticasone propionate by GOLD stage of chronic obstructive pulmonary disease: analysis from the randomised, placebo-controlled TORCH study. Respir Res. 2009;10:59.

47. Tashkin DP, Ferguson GT. Combination bronchodilator therapy in the management of chronic pulmonary disease. Respir Res. 2013;14:49.

48. Beeh KM, Derom E, Echave-Sustaeta J, et al. The lung function profile of once-daily tiotropium and olodaterol via Respimat is superior to that of twice-daily salmeterol and fluticasone propionate via Accuhaler (ENERGITO study). Int J Chron Obstruct Pulmon Dis. 2016;11:193-205.

49. Zhou Y, Zhong NS, Li X, et al. Tiotropium in early-stage chronic obstructive pulmonary disease. $N$ Engl J Med. 2017;377:923-935.

50. Calverley PM, Anderson JA, Celli B, et al. Salmeterol and fluticasone propionate and survival in chronic obstructive pulmonary disease. N Engl J Med. 2007 22;356:775-789.

51. Buhl R, Maltais F, Abrahams R, et al. Tiotropium and olodaterol fixeddose combination versus mono-components in COPD (GOLD 2-4). Eur Respir J. 2015;45:969-979.

52. Wedzicha JA, Banerji D, Chapman KR, et al. Indacaterol-glycopyrronium versus salmeterol-fluticasone for COPD. $N$ Engl J Med. 2016;374:2222-2234.

53. Zheng J, Zhong N, Newlands A, Church A, Goh AH. Efficacy and safety of once-daily inhaled umeclidinium/vilanterol in Asian patients with COPD: results from a randomized, placebo-controlled study. Int J Chron Obstruct Pulmon Dis. 2015;10:1753-1767.

54. Bateman ED, Chapman KR, Singh D, et al. Aclidinium bromide and formoterol fumarate as a fixed-dose combination in COPD: pooled analysis of symptoms and exacerbations from two six-month, multicenter, randomised studies (ACLIFORM and AUGMENT). Respir Res. 2015;16:92.

55. Singh D, Ferguson GT, Bolitschek J, et al. Tiotropium + olodaterol shows clinically meaningful improvements in quality of life. Respir Med. 2015;109:1312-1319.

56. Buhl R, Abrahams R, Grönke L, Korducki L, Flezar M, Ferguson GT. Tiotropium plus olodaterol fixed-dose combination therapy provides lung function benefits when compared with tiotropium alone, irrespective of prior treatment with a long-acting bronchodilator: post hoc analyses of two 1-year studies. Am J Respir Crit Care Med. 2015;191:A5755.

57. Ferguson GT, Pizzichini E, Flezar M, Grönke L, Korducki L. The fixed dose combination of tiotropium + olodaterol has a rapid onset of action in patients with COPD. Eur Respir J. 2015;46:PA2957.

58. Beeh KM, Westerman J, Kirsten AM, et al. The 24-h lung-function profile of once-daily tiotropium and olodaterol fixed-dose combination in chronic obstructive pulmonary disease. Pulm Pharmacol Ther. 2015;32:53-59.

59. Cazzola M, McNee W, Martinez FJ, et al. Outcomes for COPD pharmacological trials: from lung function to biomarkers. Eur Respir J. 2008;31:416-469.

60. Miravitlles M, Price D, Rabe KF, Schmidt H, Metzdorf N, Celli B. Comorbidities of patients in tiotropium clinical trials: comparison with observational studies of patients with chronic obstructive pulmonary disease. Int J Chron Obstruct Pulmon Dis. 2015;10:549-564.

61. Kern DM, Davis J, Williams SA, et al. Comparative effectiveness of budesonide/formoterol combination and fluticasone/salmeterol combination among chronic obstructive pulmonary disease patients new to controller treatment: a US administrative claims database study. Respir Res. 2015; 16:52.

62. Donohue JF, Worsley S, Zhu CQ, Hardaker L, Church A. Improvements in lung function with umeclidinium/vilanterol versus fluticasone propionate/salmeterol in patients with moderate-to-severe COPD and infrequent exacerbations. Respir Med. 2015;109:870-881.

63. Bateman ED, Ferguson GT, Barnes N, et al. Dual bronchodilation with QVA149 versus single bronchodilator therapy: the SHINE study. Eur Respir J. 2013;42:1484-1494.

64. Ofir D, Laveneziana P, Webb KA, et al. Mechanisms of dyspnea during cycle exercise in symptomatic patients with GOLD stage I chronic obstructive pulmonary disease. Am J Respir Crit Care Med. 2008:177:622-629.
65. Troosters T, Sciurba F, Battaglia S, et al. Physical inactivity in patients with COPD, a controlled multi-center pilot study. Respir Med. 2010;104:1005-1011.

66. Waschki B, Kirsten A, Holz O, et al. Physical activity is the strongest predictor of all-cause mortality in patients with COPD: a prospective cohort study. Chest. 2011;140:331-342.

67. Garcia-Aymerich J, Lange P, Benet M, et al. Regular physical activity reduces hospital admission and mortality in chronic obstructive pulmonary disease: a population based cohort study. Thorax. 2006;61:772-778.

68. Andersson M, Slinde F, Grönberg AM, et al. Physical activity level and its clinical correlates in chronic obstructive pulmonary disease: a cross-sectional study. Respir Res. 2013;14:128.

69. Hill K, Gardiner PA, Cavalheri V, et al. Physical activity and sedentary behaviour: applying lessons to chronic obstructive pulmonary disease. Intern Med J. 2015;45:474-482.

70. Reardon JZ, Lareau SC, ZuWallack R. Functional status and quality of life in chronic obstructive pulmonary disease. Am J Med. 2006;119: S32-S37.

71. Lacasse Y, Martin S, Lasserson TJ, Goldstein RS. Meta-analysis of respiratory rehabilitation in chronic obstructive pulmonary disease: a Cochrane systematic review. Eura Medicophys. 2007;43:475-485.

72. Ries AL, Bauldoff GS, Carlin BW, et al. Pulmonary rehabilitation: joint ACCP/AACVPR evidence-based clinical practice guidelines. Chest. 2007;131:4S-42S.

73. Santus P, Radovanovic D, Balzano G, et al. Improvements in lung diffusion capacity following pulmonary rehabilitation in COPD with and without ventilation inhomogeneity. Respiration. 2016;92:295-307.

74. Casaburi R, Kukafka D, Cooper CB, et al. Improvement in exercise tolerance with the combination of tiotropium and pulmonary rehabilitation in patients with COPD. Chest. 2005;127:809-817.

75. Maltais F, Iturri JB, Kirsten A, et al. Effects of 12 weeks of once-daily tiotropium and olodaterol fixed-dose combination on exercise endurance in patients with COPD. Thorax. 2014;69:A186-A187.

76. Beeh KM, Korn S, Beier J, et al. QVA149 once daily improves exercise tolerance and lung function in patients with moderate to severe COPD: the BRIGHT study. Thorax. 2012;67:A147.

77. Troosters T, Bourbeau J, Maltais F, et al. Enhancing exercise tolerance and physical activity in COPD with combined pharmacological and non-pharmacological interventions: PHYSACTO randomised, placebocontrolled study design. BMJ Open. 2016;6:e010106.

78. O'Donnell DE, Casaburi R, Frith P, et al. Effects of combined tiotropium/olodaterol on inspiratory capacity and exercise endurance in COPD. Eur Respir J. 2017;49:1601348.

79. Beeh KM, Burgel PR, Franssen FM, et al. How do dual long-acting bronchodilators prevent exacerbations of chronic obstructive pulmonary disease? Am J Respir Crit Care Med. 2017;196:139-149.

80. Qaseem A, Wilt TJ, Weinberger SE, et al. Diagnosis and management of stable chronic obstructive pulmonary disease: a clinical practice guideline update from the American College of Physicians, American College of Chest Physicians, American Thoracic Society, and European Respiratory Society. Ann Intern Med. 2011;155:179-191.

81. Koblizek V, Chlumsky J, Zindr V, et al. Chronic obstructive pulmonary disease: official diagnosis and treatment guidelines of the Czech Pneumological and Phthisiological Society - a novel phenotypic approach to COPD with patient-oriented care. Biomed Pap Med Fac Univ Palacky Olomouc Czech Repub. 2013;157:189-201.

82. Russi EW, Karrer W, Brutsche M, et al. Diagnosis and management of chronic obstructive pulmonary disease: the Swiss guidelines. Respiration. 2013;85:160-174.

83. Vogelmeier C, Hederer B, Glaab T, et al. Tiotropium versus salmeterol for the prevention of exacerbations of COPD. N Engl J Med. 2011; 364:1093-1103.

84. Decramer ML, Chapman KR, Dahl R, et al. Once-daily indacaterol versus tiotropium for patients with severe chronic obstructive pulmonary disease (INVIGORATE): a randomised, blinded, parallel-group study. Lancet Respir Med. 2013;1:524-533.

85. Vestbo J, Anderson J, Brook RD, et al. Study to understand mortality and morbidity in COPD (SUMMIT). Eur Respir J. 2015;46:OA3476. 
86. Pecchiari MM, Santus P, Radovanovic D, D’Angelo EG. The acute effects of long acting bronchodilators on small airways detected in COPD patients by single breath N2 test and lung P-V curve. $J$ Appl Physiol (1985). Epub 2017 Aug 3.

87. Tagaya E, Yagi O, Sato A, et al. Effect of tiotropium on mucus hypersecretion and airway clearance in patients with COPD. Pulm Pharmacol Ther. 2016;39:81-84

88. Jehn M, Schmidt-Trucksäss A, Meyer A, et al. Association of daily physical activity volume and intensity with COPD severity. Respir Med. 2011;105:1846-1852.

89. Wedzicha JA, Decramer M, Seemungal TA. The role of bronchodilator treatment in the prevention of exacerbations of COPD. Eur Respir J. 2012;40:1545-1554.

90. Santus P, Radovanovic D, Di Marco S, et al. Effect of indacaterol on lung deflation improves cardiac performance in hyperinflated COPD patients: an interventional, randomized, double-blind clinical trial. Int J Chron Obstruct Pulmon Dis. 2015;10:1917-1923.

91. Hawkins NM, Virani S, Ceconi C. Heart failure and chronic obstructive pulmonary disease: the challenges facing physicians and health services. Eur Heart J. 2013;34:2795-2803.

92. Celli B, Decramer M, Leimer I, et al. Cardiovascular safety of tiotropium in patients with COPD. Chest. 2010;137:20-30.

93. Rottenkolber M, Rottenkolber D, Fischer R, et al. Inhaled $\beta_{2}$-agonists/ muscarinic antagonists and acute myocardial infarction in COPD patients. Respir Med. 2014;108:1075-1090.

94. Rabe KF, Timmer W, Sagkriotis A, Viel K. Comparison of a combination of tiotropium plus formoterol to salmeterol plus fluticasone in moderate COPD. Chest. 2008;134:255-262.

95. Vogelmeier C, Bateman ED, Pallante J, et al. Efficacy and safety of once-daily QVA149 compared with twice-daily salmeterol-fluticasone in patients with chronic obstructive pulmonary disease (ILLUMINATE): a randomized, double-blind, parallel group study. Lancet Respir Med. 2013;1:51-60.

96. Donohue JF, Hanania NA, Make B, et al. One-year safety and efficacy study of arformoterol tartrate in patients with moderate to severe COPD. Chest. 2014;146(6):1531-1542.

97. Vogelmeier C, Paggiaro PL, Dorca G, et al. Efficacy and safety of aclidinium/formoterol versus salmeterol/fluticasone: a phase 3 COPD study. Eur Respir J. 2016;48:1030-1039.

98. Global Initiative for Chronic Obstructive Lung Disease. Global Strategy for the Diagnosis, Management, and Prevention of COPD. Bethesda (MD): GOLD; 2017.

99. Koblizek V, Milenkovic B, Barczyk A, et al. Phenotypes of COPD patients with a smoking history in Central and Eastern Europe: the POPE study. Eur Respir J. 2017;49:1601446.

100. Global Initiative for Chronic Obstructive Lung Disease. Global Strategy for the Diagnosis, Management, and Prevention of COPD. Bethesda (MD): GOLD; 2016.

101. Tudoric N, Koblizek V, Miravitlles M, et al. GOLD 2017 on the way to a phenotypic approach? Analysis from the phenotypes of COPD in Central and Eastern Europe (POPE) cohort. Eur Respir J. 2017;49:1602518.

102. Pascoe SJ, Lipson DA, Locantore N, et al. A phase III randomised controlled trial of single-dose triple therapy in COPD: the IMPACT protocol. Eur Respir J. 2016;48:320-330.

103. Kozma CM, Paris AL, Plauschinat CA, et al. Comparison of resource by COPD patients on inhaled therapies with long-acting bronchodilators: a database study. BMC Pulm Med. 2011;11:61.

104. van Boven J, Kocks JW, Postma MJ. Cost-effectiveness and budget impact of the fixed-dose dual bronchodilator combination tiotropiumolodaterol for patients with COPD in the Netherlands. Int J Chron Obstruct Pulmon Dis. 2016;11:2191-2201.

105. Boehringer Ingelheim. Comparing the efficacy of tiotropium + olodaterol $(5 / 5 \mu \mathrm{g})$ fixed dose combination (FDC) over tiotropium $5 \mu \mathrm{g}$ in reducing moderate to severe exacerbations in patients with severe to very severe chronic obstructive pulmonary disease. Available from: https:/clinicaltrials.gov/ct2/show/NCT02296138. NLM identifier: NCT02296138. Accessed October 31, 2017.
106. Miravitlles M, Vogelmeier C, Roche N, et al. A review of national guidelines for management of COPD in Europe. Eur Respir J. 2016; 47:625-637.

107. Barnes PJ. Corticosteroid resistance in patients with asthma and chronic obstructive pulmonary disease. J Allergy Clin Immunol. 2013;131:636-645.

108. Pauwels RA, Lofdahl CG, Laitinen LA, et al. Long-term treatment with inhaled budesonide in persons with mild chronic obstructive pulmonary disease who continue smoking. N Engl J Med. 1999;340:1948-1953.

109. Vestbo J, Sorensen T, Lange P, et al. Long-term effect of inhaled budesonide in mild and moderate chronic obstructive pulmonary disease: a randomised controlled trial. Lancet. 1999;353:1819-1823.

110. Lung Health Study Research Group. Effect of inhaled triamcinolone on the decline in pulmonary function in chronic obstructive pulmonary disease. N Engl J Med. 2000;343:1902-1909.

111. Burge PS, Calverley PM, Jones PW, et al. Randomised, double blind, placebo controlled study of fluticasone propionate in patients with moderate to severe chronic obstructive pulmonary disease: the ISOLDE trial. BMJ. 2000;320:1297-1303.

112. Aaron SD, Fergusson D, Marks GB, et al. Counting, analysing and reporting exacerbations of COPD in randomised controlled trials. Thorax. 2008;63:122-128.

113. La Vecchia C, Fabbri LM. Prevention of death in COPD. $N$ Engl $J$ Med. 2007;356:2211-2212.

114. Suissa S, Ernst P, Vandemheen KL, Aaron SD. Methodological issues in therapeutic trials of COPD. Eur Respir J. 2008;31:927-933.

115. Spencer S, Karner C, Cates CJ, Evans DJ. Inhaled corticosteroids versus long-acting $\beta_{2}$-agonists for chronic obstructive pulmonary disease. Cochrane Database Syst Rev. 2011:CD0070033.

116. Vestbo J, Leather D, Bakerly ND, et al. Effectiveness of fluticasone furoate-vilanterol for COPD in clinical practice. $N$ Engl J Med. 2016; 375:1253-1260.

117. Davis KJ, Landis SH, Oh YM, et al. Continuing to Confront COPD International Physician Survey: physician knowledge and application of COPD management guidelines in 12 countries. Int J Chron Obstruct Pulmon Dis. 2014;10:39-55.

118. Brusselle G, Proce D, Gruffydd-Jones K, et al. The inevitable drift to triple therapy in COPD: an analysis of prescribing pathways in the UK. Int J Chron Obstruct Pulmon Dis. 2015;10:2207-2217.

119. Price D, Brusselle G, West G, et al. Management of COPD in the UK primary-care setting: an analysis of real-life prescribing patterns. Int J Chron Obstruct Pulmon Dis. 2014;9:889-904.

120. Barrecheguren M, Monteagudo M, Ferrer J, et al. Treatment patterns in COPD patients newly diagnosed in primary care: a population-based study. Respir Med. 2016;111:47-53.

121. Perez X, Wisnivesky JP, Lurslurchachai L, et al. Barriers to adherence to COPD guidelines among primary care providers. Respir Med. 2012;106:374-381.

122. Salinas GD, Williamson JC, Kalhan R, et al. Barriers to adherence to chronic obstructive pulmonary disease guidelines by primary care physicians. Int J Chron Obstruct Pulmon Dis. 2011;6:171-179.

123. Boros PW, Martusewicz-Boros MM. Reversibility of airway obstruction vs bronchodilatation: do we speak the same language? COPD. 2012;9:213-215.

124. Decramer M, Bartsch P, Pauwels R, et al. Management of COPD according to guidelines: a national survey among Belgian physicians. Monaldo Arch Chest Dis. 2003;59:62-80.

125. Miravittles M, Andreu I, Romero Y, et al. Difficulties in differential diagnosis of COPD and asthma in primary care. Br J Gen Pract. 2012; 62:e68-e75.

126. Glaab T, Banik N, Rutshmann OT, Wencker M. National survey of guideline compliant COPD management among pulmonologists and primary care physicians. COPD. 2006;3:141-148.

127. Lucas AE, Smeenk FW, Smeele IJ, van Schayck CP. Overtreatment with inhaled corticosteroids and diagnostic problems in primary care patients, an exploratory study. Fam Pract. 2008;25:86-91.

128. Ernst P, Saad N, Suissa S. Inhaled corticosteroids in COPD: the clinical evidence. Eur Respir J. 2015;45:525-537. 
129. Flynn RW, MacDonald TM, Hapca A, et al. Quantifying the real life risk profile of inhaled corticosteroids in COPD by record linkage analysis. Respir Res. 2014;15:141.

130. Price D, Yawn B, Brusselle G, Rossi A. Risk-to-benefit ratio of inhaled corticosteroids in patients with COPD. Prim Care Respir J. 2013;22:92-100.

131. Babu KS, Kastelik JA, Morjaria JB. Inhaled corticosteroids in chronic obstructive pulmonary disease: a pro-con perspective. $\mathrm{Br} \mathrm{J} \mathrm{Clin}$ Pharmacol. 2014;78:282-300.

132. Lee MC, Lee $\mathrm{CH}$, Chien SC, et al. Inhaled corticosteroids increase the risk of pneumonia in patients with chronic obstructive pulmonary disease: a nationwide cohort study. Medicine (Baltimore). 2015;94:e1723.

133. DiSantostefano RL, Sampson T, Le HV, Hinds D, Davis KJ, Bakerly ND. Risk of pneumonia with inhaled corticosteroid versus long-acting bronchodilator regimens in chronic obstructive pulmonary disease: a new-user cohort study. PLoS One. 2014;9:e97149.

134. Crim C, Calverley PM, Anderson JA, et al. Pneumonia risk in COPD patients receiving inhaled corticosteroids alone or in combination: TORCH study results. Eur Respir J. 2009;34:641-647.

135. Festic E, Bansal V, Gupta E, Scanlon PD. Association of inhaled corticosteroids with incident pneumonia and mortality in COPD patients: systematic review and meta-analysis. COPD. 2016;13:312-326.

136. Ernst $P$, Gonzalez AV, Brassard $P$, et al. Inhaled corticosteroid use in chronic obstructive pulmonary disease and the risk of hospitalization for pneumonia. Am J Respir Crit Care Med. 2007;176:162-166.

137. Suissa S, Coulombe J, Ernst P. Discontinuation of inhaled corticosteroids in COPD and the risk reduction of pneumonia. Chest. 2015; 148:1177-1183

138. Miravittles M, Soler-Cataluña JJ, Calle M, Soriano JB. Treatment of COPD by clinical phenotypes: putting old evidence into clinical practice. Eur Respir J. 2013;41:1252-1256.

139. Hardin M, Silverman E, Barr RG, et al. The clinical features of the overlap between COPD and asthma. Respir Res. 2011;12:127.

140. Global Initiative for Asthma. Global Strategy for Asthma Management and Prevention. Bethesda (MD): GINA; 2017.

141. Global Initiative for Chronic Obstructive Lung Disease, Global Initiative for Asthma. Diagnosis of diseases of chronic airflow limitation: asthma, COPD, and asthma-COPD overlap syndrome (ACOS). 2015. Available from: http://goldcopd.org/asthma-copd-asthma-copdoverlap-syndrome. Accessed October 31, 2017.

142. Lim HS, Choi SM, Lee J, et al. Responsiveness to inhaled corticosteroid treatment in patients with asthma-chronic obstructive pulmonary disease overlap syndrome. Ann Allergy Asthma Immunol. 2014;113: 652-657.

143. Postma DS, Rabe KF. The asthma-COPD overlap syndrome. $N$ Engl J Med. 2015;373:1241-1249.

144. Barnes PJ. Therapeutic approaches to asthma-chronic obstructive pulmonary disease overlap syndromes. J Allergy Clin Immunol. 2015; 136:531-545.

145. D'Urzo A, Donohue JF, Kardos P, et al. A re-evaluation of the role of inhaled corticosteroids in the management of patients with chronic obstructive pulmonary disease. Expert Opin Pharmacother. 2015;16:1845-1860.
146. Siddiqui SH, Guasconi A, Vestbo J, et al. Blood eosinophils: a biomarker of response to extrafine beclomethasone/formoterol in chronic obstructive pulmonary disease. Am J Respir Crit Care Med. 2015;192: 523-525.

147. Pascoe S, Locantore N, Dransfield MT, et al. Blood eosinophil counts, exacerbations, and response to the addition of inhaled fluticasone furoate to vilanterol in patients with chronic obstructive pulmonary disease: a secondary analysis of data from two parallel randomised controlled trials. Lancet Respir Med. 2015;3:435-442.

148. Watz H, Tetzlaff K, Wouters E, et al. Blood eosinophil count and exacerbations in severe chronic obstructive pulmonary disease after withdrawal of inhaled corticosteroids: a post-hoc analysis of the WISDOM trial. Lancet Respir Med. 2016;4:390-398.

149. Barnes NC, Sharma R, Lettis S, Calverley PM. Blood eosinophils as a marker of response to inhaled corticosteroids in COPD. Eur Respir J. 2016;47:1374-1382.

150. Jarad NA, Wedzicha JA, Burge PS, Calverley PM. An observational study of inhaled corticosteroid withdrawal in stable chronic obstructive pulmonary disease. Respir Med. 1999;93:161-166.

151. van der Valk P, Monninkhof E, van der Palen J, et al. Effect of discontinuation of inhaled corticosteroids in patients with chronic obstructive pulmonary disease: the COPE study. Am J Respir Crit Care Med. 2002;166:1358-1363.

152. Choudhury AB, Dawson CM, Kilvington HE, et al. Withdrawal of inhaled corticosteroids in people with COPD in primary care: a randomised controlled trial. Respir Res. 2007;8:93.

153. Wouters EF, Postma DS, Fokkens B, et al. Withdrawal of fluticasone propionate from combined salmeterol/fluticasone treatment in patients with COPD causes immediate and sustained disease deterioration: a randomised controlled trial. Thorax. 2005;60:480-487.

154. Magnussen H, Disse B, Rodriguez-Roisin R, et al. Withdrawal of inhaled glucocorticoids and exacerbations of COPD. $N$ Engl J Med. 2014;371:1285-1294.

155. Yawn BP, Suissa S, Rossi A. Appropriate use of inhaled corticosteroids in COPD: the candidates for safe withdrawal. NPJ Prim Care Respir Med. 2016;26:16068.

156. Magnussen $\mathrm{H}$, Tetzlaff $\mathrm{K}$, Bateman ED, et al. Lung function changes over time following withdrawal of inhaled corticosteroids in patients with severe COPD. Eur Respir J. 2016;47:651-654.

157. Calzetta L, Matera MG, Braido F, et al. Withdrawal of inhaled corticosteroids in COPD: a meta-analysis. Pulm Pharmacol Ther. 2017; 45:148-158.

158. Rossi A, van der Molen T, del Olmo R, et al. INSTEAD: a randomised switch trial of indacaterol versus salmeterol/fluticasone in moderate COPD. Eur Respir J. 2014;44:1548-1556.

159. Kaplan AG. Applying the wisdom of stepping down inhaled corticosteroids in patients with COPD: a proposed algorithm for clinical practice. Int J Chron Obstruct Pulmon Dis. 2015;10:2535-2548.

160. Miravitlles M, D’Urzo A, Singh D, Koblizek V. Pharmacological strategies to reduce exacerbation risk in COPD: a narrative review. Respir Res. 2016;17:112.
International Journal of COPD

\section{Publish your work in this journal}

The International Journal of COPD is an international, peer-reviewed journal of therapeutics and pharmacology focusing on concise rapid reporting of clinical studies and reviews in COPD. Special focus is given to the pathophysiological processes underlying the disease, intervention programs, patient focused education, and self management protocols.

\section{Dovepress}

This journal is indexed on PubMed Central, MedLine and CAS. The manuscript management system is completely online and includes a very quick and fair peer-review system, which is all easy to use. Visit http://www.dovepress.com/testimonials.php to read real quotes from published authors. 